\title{
Fatigue strength improvement of MIG-welded joint by shot peening
}

\begin{abstract}
In this study, the effect of controlled shot peening (CSP) treatment on the fatigue strength of an ASTM A516 grade 70 carbon steel MIG-welded joint has been studied quantitatively. Metallurgical modifications, hardness, elemental compositions, and internal discontinuities, such as porosity and inclusions found in treated and untreated fusion welded joints, were characterized. The fatigue results of as-welded and peened skimmed joints were compared. It was observed that the effect of the CSP and skimming processes improved the fatigue life of the fusion weld by $63 \%$ on MIG-welded samples.
\end{abstract}

Keyword: Shot peening; Fatigue strength; Welded joints 